\title{
BIOMIMETIC SYNTHESIS, CHARACTERIZATION AND EVALUATION OF ANTIOXIDANT, ANTIMICROBIAL EFFICACY OF SILVER NANOPARTICLES USING ANREDERA CORDIFOLIA LEAF EXTRACT
}

\author{
RAJATHI K ${ }^{1 *}$, SUJA $S^{2}$ \\ ${ }^{1}$ PG and Research Department of Biochemistry, Dr. N. G. P Arts and Science College, Coimbatore, Tamil Nadu, India. ${ }^{2}$ Department of \\ Biochemistry, Bharathiar University, Coimbatore, Tamil Nadu, India. Email: Rajathingp@gmail.com
}

Received: 28 December 2016, Revised and Accepted: 19 January 2017

\begin{abstract}
Objective: This study is focused on the biosynthesis of silver nanoparticles (AgNPs) using aqueous extract of Anredera cordifolia and to investigate the free radical scavenging potential, antimicrobial activity of the nanoparticles against different human pathogens.

Methods: The formation of AgNPs was indicated by the color change from colorless to reddish brown. Biosynthesized AgNPs were characterized using several techniques, viz., ultraviolet (UV)-visible spectroscopy, Fourier transform infrared, X-ray diffraction (XRD), transmission electron microscopy (TEM), scanning electron microscopy (SEM), and energy dispersive X-ray analysis. The free radical scavenging potential was measured by 2, 2-diphenyl-1-picrylhydrazyl (DPPH), ferric reducing antioxidant power (FRAP) assay, antimicrobial activity against six microorganisms was tested using disc diffusion method.
\end{abstract}

Results: UV-visible spectral analysis showed silver surface plasmon resonance band at $426 \mathrm{~nm}$. The crystalline morphology and size of the nanoparticles were determined by TEM, SEM, and XRD studies which showed the average size of the nanoparticles in the range 40-60 $\mathrm{nm}$. The biologically synthesized nanoparticles efficiently inhibited pathogenic organisms such as Escherichia coli, Staphylococcus aureus, Klebsiella pneumonia, Pseudomonas aeruginosa, and Proteus vulgaris. The biosynthesized nanoparticles might serve as a potent antioxidant as revealed by DPPH assay and FRAP assay.

Conclusion: The biosynthesis of AgNPs had several advantages in pharmaceutical applications as well as large-scale commercial production.

Keywords: Silver nanoparticle, Anredera cordifolia leaf, Scanning electron microscopy, Transmission electron microscopy, X-ray diffraction, Antioxidant, Antimicrobial.

(c) 2017 The Authors. Published by Innovare Academic Sciences Pvt Ltd. This is an open access article under the CC BY license (http://creativecommons. org/licenses/by/4. 0/) DOI: http://dx.doi.org/10.22159/ajpcr.2017.v10i4.16819

\section{INTRODUCTION}

Nanotechnology can be termed as the synthesis, characterization, exploration, and application of nanosized $(1-100 \mathrm{~nm})$ materials for the development of science. The intrinsic properties of metal nanoparticles are determined by size, shape, composition, crystallinity, and morphology. It is a field of science which deals with production, manipulation and use of materials ranging in nanometers. In nanotechnology nanoparticles research is an important aspect due to its innumerable applications. The nanoparticles have a wide range of applications, as in combating microbes [1], biolabeling [2], and in the treatment of cancer [3]. The antibacterial activity of silver species is known since ancient times [4] and it has been demonstrated that, at low concentrations, silver is nontoxic to human cells [5]. It has also been reported that $\mathrm{Ag}^{+}$ions uncouple the respiratory chain from oxidative phosphorylation or collapse the proton-motive force across the cytoplasmic membrane [6]. The interaction of $\mathrm{Ag}^{+}$with bacteria is directly related to the size and shape of the nanoparticles [7].

The research in nanotechnology highlights the possibility of green chemistry route to produce technologically valuable nanomaterials. In recent times, prevalence resistance to antimicrobial agents has emerged as a major health problem [8]. Biosynthesis of metallic nanoparticles is an eco-friendly process in the field of applied nanotechnology [9].

Among all metal-nanoparticles, silver nanoparticles (AgNPs) exhibit tremendous applications in spectrally selective coatings for solar energy absorption, optical receptors, biolabeling, intercalation materials for electrical batteries, filters, antimicrobial agents, and sensors [10]. AgNP-embedded antimicrobial paint [11] is a promising area of ecofriendly applications. Hence, a variety of techniques including physical and chemical methods have been developed to synthesize AgNPs, the physical methods [12] are highly expensive and chemical methods are harmful to the environment [13]. Therefore, there is a growing need to develop environmentally benign nanoparticle synthesis processes that do not use toxic chemicals in the synthesis protocols.

It is generally recognized that AgNPs may attach to the cell wall, which disturbs cell-wall permeability and cellular respiration. The nanoparticles may also penetrate inside the cell causing damage by interacting with phosphorus and sulfur containing compounds such as DNA and protein. Another possible contribution to the bactericidal properties of silver particles is the release of silver ions [14].

Many researchers demonstrated the green synthesis of AgNPs including bacteria, actinomycetes, fungi and plants. Whereas, the plant materials have been successfully applied for AgNPs synthesis, due to its potential medicinal property, availability, possibility of faster rate of synthesis and may also reduce the steps in downstream processing, thereby making the process cost efficient $[15,16]$.

This study was designed with a simple, cost-effective, and environmentally synthesis method of AgNPs at ambient conditions using Anredera cordifolia leaves as a reducing and stabilizing agent. In this study, we have explored the green synthesis of AgNPs using A. cordifolia leaf extract. Synthesized nanoparticles were characterized by ultraviolet (UV)-visible spectroscopy, X-ray diffraction (XRD), 
Fourier transform infrared (FTIR), scanning electron microscopy (SEM), and transmission electron microscopy (TEM). Furthermore, the antimicrobial activity of synthesized AgNPs against Escherichia coli, Staphylococcus aureus, Klebsiella pneumonia, Pseudomonas aeruginosa, and Proteus vulgaris were tested.

\section{METHODS}

\section{Collection of plant material}

The leaves of $A$. cordifolia were collected from Gudalur and have authenticated (Certificate No. BSI/SRC/5/23/2015/Tech/406 dated: $24 / 2 / 2015$ ) by Botanical survey of India (BSI), Coimbatore division, Tamil Nadu State, India. The leaves were washed with distilled water to remove the soil and other dust particles. After washing, the leaves were shade dried and powdered. The powdered leaves were used for the assay.

\section{Preparation of the extract}

About $50 \mathrm{~g}$ of leaf powder was weighed and it is mixed with $100 \mathrm{ml}$ of distilled water and boiled for 5 minutes. After cooling, the solution was filtered through Whatman no. 1 filter paper. The filtered samples were collected in a conical flask. The obtained extract was used for the synthesis of AgNPs.

\section{Biosynthesis of AgNPs}

About $1 \mathrm{~mm}$ silver nitrate solution was prepared and used for synthesis of AgNPs. $10 \mathrm{ml}$ of the plant extract was added into $200 \mathrm{ml}$ of aqueous solution of $1 \mathrm{~mm}$ silver nitrate the color change of the leaf extract from brown to yellow was noted periodically. Then the extract was incubated at room temperature for further incubation till $72 \mathrm{hrs}$. After incubation, the AgNPs were synthesized from the leaf and centrifuged at $10000 \mathrm{rpm}$ for 20 minutes and the pellet was characterized. The collected pellets were stored at $-4^{\circ} \mathrm{C}$. Reduction of silver ion into silver particle during exposure to the plant extract could be followed by color change. AgNP exhibited light green-dark brown in aqueous solution due to the surface plasmon resonance phenomenon to monitor the AgNP synthesis.

\section{Characterization of AgNPs}

Characterization of nanoparticles is important to understand and control nanoparticles synthesis and applications. The AgNPs can be characterized by UV-visible spectroscopy, SEM, TEM, XRD, and FTIR spectroscopy.

\section{UV-visible spectral analysis}

The color change in reaction mixture (silver metal ion solution+aqueous extract of A. cordifolia) was recorded through visual observations. The bioreduction of silver ions in aqueous solution was monitored by periodic sampling of aliquots $(1 \mathrm{ml})$ and subsequent measuring was carried out using UV-visible spectroscopy (Elico UV-visible spectrophotometer).

\section{SEM analysis}

SEM analysis was done using Hitachi S-4500 SEM machine. Thin films of the sample were prepared on a carbon coated copper grid by just dropping a very small amount of the sample on the grid, extra solution was removed using a blotting paper and then the film on the SEM grid were allowed to dry under a mercury lamp for 5 minutes.

\section{TEM analysis}

Morphology and size of the AgNPs were investigated using TEM images. TEM observations were performed on a Philips-TECNAI 10 instrument. Thin films of the sample were prepared on a carbon coated copper grid by just dropping a very small amount of the sample on the grid, extra solution was removed using a blotting paper and then the film was allowed to dry overnight.

\section{XRD analysis}

XRD measurements of the reduced AgNPs were recorded on XRD (X'pert panalytical) instrument operating at a voltage of $40 \mathrm{kV}$ and current of $30 \mathrm{~mA}$ with $\mathrm{Cu} \mathrm{K}(\alpha)$ radiation to determine the crystalline phase and material identification. The samples were taken in lids and put under instrument for analysis.

\section{FTIR analysis}

Perkin-Elmer spectrometer FTIR Spectrum ranging from 500 to $4000 / \mathrm{cm}$ at a resolution of $4 / \mathrm{cm}$ was used for the analysis. The sample was mixed with potassium bromide crystals. Thin sample disc was prepared by pressing with the disc preparing machine and placed in FTIR for the analysis of the nanoparticles as well as for the biosynthesized AgNPs.

\section{Antioxidant activity of biosynthesized AgNPs}

\section{2, 2-diphenyl-1-picrylhydrazyl (DPPH) free radial scavenging} activity

The antioxidant activity of the sample was determined in terms of hydrogen donating or radical scavenging ability, using the stable radical DPPH, according to the method of Blois (1958). The sample extracts at various concentrations $(20-100 \mu \mathrm{g})$ were taken and the volume was adjusted to $100 \mu \mathrm{l}$ with methanol. $5 \mathrm{ml}$ of $0.1 \mathrm{~mm}$ methanolic solution of DPPH was added and allowed to stand for 20 minutes at $27^{\circ} \mathrm{C}$. The absorbance of the sample was measured at $517 \mathrm{~nm}$.

Percentage radical scavenging activity of the sample was calculated as follows:

$\%$ DPPH radical scavenging activity=(Control OD-sample OD/control OD) $\times 100$

The analysis was performed in triplicate. The sample concentration providing $50 \%$ inhibition $\left(\mathrm{IC}_{50}\right)$ under the assay condition was calculated from the graph of inhibition percentage against AgNPs concentration.

\section{Ferric reducing antioxidant power (FRAP) assay}

The FRAP assay was used to estimate the reducing capacity of the sample, according to the method of Benzie and Strain, 1996. The FRAP reagent contained $2.5 \mathrm{ml}$ of a $10 \mathrm{~mm}$ TPTZ solution in $40 \mathrm{~mm} \mathrm{HCl}, 2.5 \mathrm{ml}$ of $20 \mathrm{~mm} \mathrm{FeCl} 3.6 \mathrm{H} 20$ and $25 \mathrm{ml}$ of $300 \mathrm{~mm}$ acetate buffer (pH3.6). It was freshly prepared and warmed at $37^{\circ} \mathrm{C} .900 \mu \mathrm{l}$ FRAP reagent was mixed with $90 \mu \mathrm{l}$ water and $10 \mu \mathrm{l}$ of the sample. The reaction mixture was incubated at $37^{\circ} \mathrm{C}$ for 30 minutes, and the absorbance was measured at $593 \mathrm{~nm}$.

\section{Antibacterial activity of biosynthesized AgNPs Preparation of inocula}

The test organisms were subcultured by streaking them on nutrient agar (NA), followed by incubation for $24 \mathrm{hrs}$ at $37^{\circ} \mathrm{C}$. Several colonies of each bacterial species were transferred to sterile nutrient broth. The suspensions were mixed for $15 \mathrm{sec}$ and incubated for $24 \mathrm{hrs}$ at $37^{\circ} \mathrm{C}$ on an orbital incubator shaker. Working concentration of the microbial suspension was prepared in $3 \mathrm{ml}$ of sterile saline to turbidity equivalent to $0.5 \mathrm{McF}$ arland scale (i.e., adjusting the optical density to 0.1 at $600 \mathrm{~nm}$ ), yielding a cell density of $1-2 \times 105 \mathrm{CFU} / \mathrm{mL}$. V.

\section{Procedure}

NA plates were seeded with $8 \mathrm{~h}$ broth culture of different bacteria. In each of these plates, wells were cut out using sterile Cork Borer. Using sterilized dropping pipettes, different concentrations $(500,1000,1500$ and $2000 \mu \mathrm{g} /$ well) of sample was carefully added into the wells and allowed to diffuse at room temperature for $2 \mathrm{hrs}$. The plates were then incubated at $37^{\circ} \mathrm{C}$ for $18-24 \mathrm{hrs}$. Gentamicin $(10 \mu \mathrm{g})$ was used as positive controls and dimethy sulfoxide as negative control. The antimicrobial activity was evaluated by measuring the diameter of inhibition zone.

\section{RESULTS AND DISCUSSION}

Biosynthesis of AgNPs from A. cordifolia Linn.

The periodical color change in reaction mixture containing silver nitrate and A. cordifolia Linn., extract was monitored for $24 \mathrm{hrs}$. 
Reduction of silver ion into silver particles during exposure to the plant extracts was observed as a result of the color change. AgNPs exhibit dark yellowish-brown color in aqueous solution due to the surface plasmon resonance phenomenon. From the results, the synthesis of AgNPs by the plant extract was confirmed by the change of color from green to dark brown during various time intervals as shown in Table 1. Rajakumar and Abdul Rahuman, 2011 reported that the characteristic brown color of silver solutions provided a convenient spectroscopic signature to indicate their formation [17]. This has been further supported by Deb, 2014 in the synthesis of AgNPs using plant extracts of Brassica oleracea capitata (Cabbage) and Phaseolus vulgar and their antibacterial properties [18].

\section{Characterization of AgNPs}

\section{$U V$-visible spectroscopic analysis of biosynthesized AgNPs}

UV-visible spectroscopy is one of the most widely used techniques for structural characterization of AgNPs. Fig. 1 shows the UV-visible spectra recorded from the reaction medium after $24 \mathrm{hrs}$.

Absorption spectra of AgNPs formed in the reaction media had absorbance peak at $426 \mathrm{~nm}$. Broadening of peak indicates that the particles are poly-dispersed. The frequency and width of the surface plasmon absorption depends on the size and shape of the metal nanoparticles as well as on the dielectric constant of the metal itself and the surrounding medium. Similar phenomenon was reported by Firdhouse and Lalitha, 2013 [19].

\section{SEM analysis of biosynthesized AgNPs}

The SEM image is showing the high density of biosynthesized AgNPs from aqueous extract of $A$. cordifolia Linn. further confirmed the development of silver nanostructure. The SEM image Fig. 2 shows the formation of porous surface with spherical nanoparticles.

Biosynthesized AgNP was further characterized and the size was confirmed by SEM analysis. The SEM image showing high density biosynthesized AgNPs from aqueous extract of A. cordifolia that confirmed the development of silver nanostructure. The SEM analysis showed the particle size between 40 and $60 \mathrm{~nm}$.

\section{TEM analysis of biosynthesized AgNPs}

The TEM image is showing the high density of biosynthesized AgNPs from aqueous extract the A. cordifolia Linn., further confirmed the development of silver nanostructure. The TEM image has shown the distribution of individual silver particles as well as the formation of number of aggregates. The morphology of the AgNPs was predominately spherical and aggregated into larger well-defined morphology observed in the micrograph in the Fig. 3. The nanoparticles were not in direct contact even within the aggregates, indicating stabilization of the nanoparticle by a capping agent. The TEM image shows the distribution of the high density AgNPs synthesized/organized by the aqueous extract $A$. cordifolia Linn.

\section{XRD analysis of biosynthesized AgNPs}

The biosynthesis of silver nanostructure by employing $A$. cordifolia leaf extract was further demonstrated and confirmed by characteristic peaks observed in the XRD image (Fig. 4).

XRD is a very important method to characterize the structure of crystalline material and used for the lattice parameters analysis of single

Table 1: Periodical color change of the biosynthesized AgNPs

\begin{tabular}{ll}
\hline Period (hrs) & Color change \\
\hline 0 & No color change \\
6 & Green \\
12 & Pale brown \\
24 & Dark brown \\
\hline
\end{tabular}

AgNPs: Silver nanoparticles crystals, or the phase, texture or even stress analysis of samples. The XRD spectrum showed intense peaks the whole spectrum of $2 \theta$ value ranging from 20 to 80 and indicated that the structure of AgNPs is face centered cubic (FCC). XRD of the AgNPs showed two distinct diffraction peaks at $38.12^{\circ}$ and $44.31^{\circ}$ and these $2 \theta$ values were indexed in the angle values of (111) and (200) crystalline planes of cubic silver. The

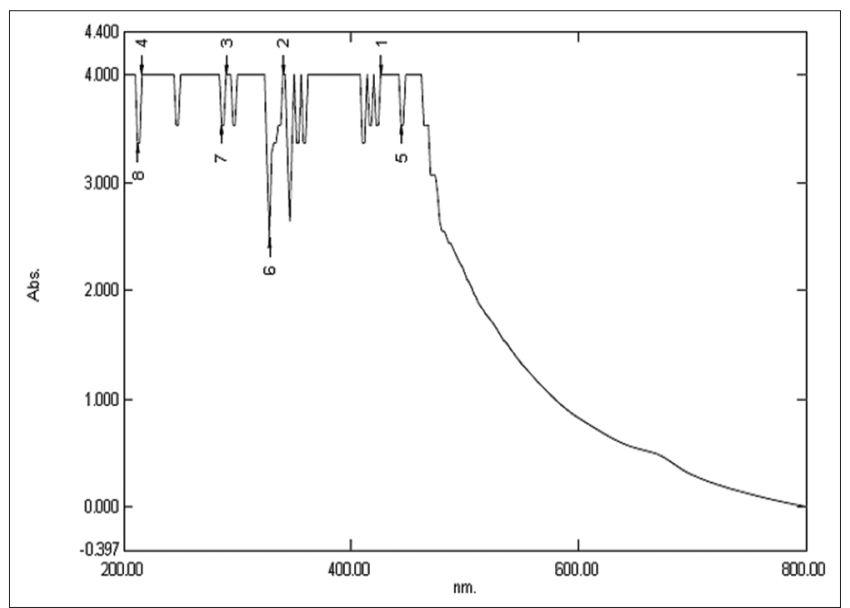

Fig. 1: Ultraviolet-visible spectroscopy analysis

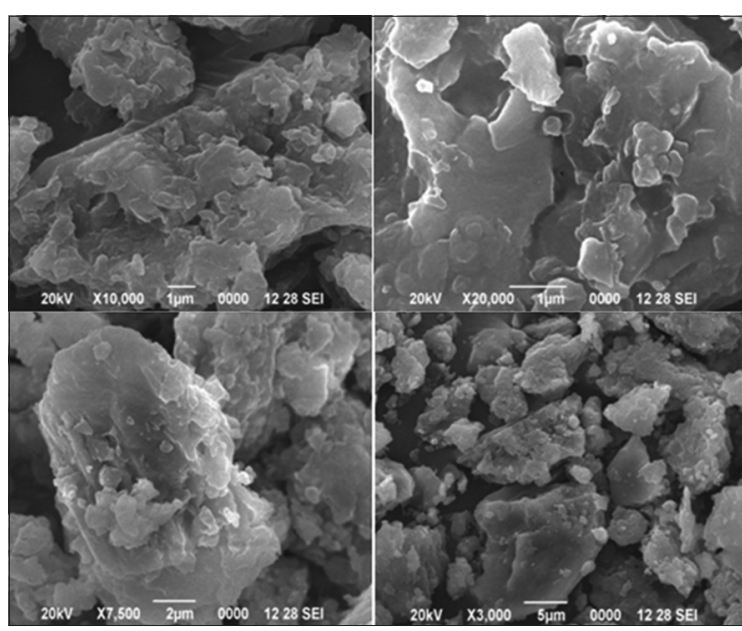

Fig. 2: Scanning electron microscopy analysis

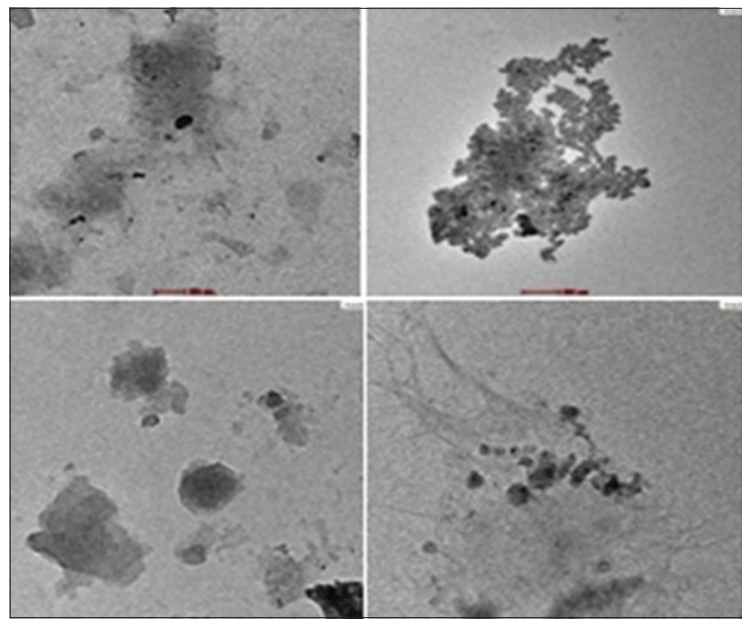

Fig. 3: Transmission electron microscopy image of biosynthesized silver nanoparticles 
lattice constant calculated from this pattern was $\mathrm{a}=4.085 \mathrm{~A}^{\circ}$ and the data obtained were matched with the database of Joint Committee on Powder Diffraction Standards file No. 04-4387. The average particle size of AgNPs synthesized by the present green method can be calculated using Debye-Scherer equation.

$D=K \lambda / \beta \cos \theta$

Where $\mathrm{D}=$ the crystallite size of AgNPs particles $\lambda=$ The wavelength of X-ray source $(0.1541 \mathrm{~nm})$ used in XRD $\beta=$ The full width at half maximum of the diffraction peak $\mathrm{K}=$ The Scherer constant with value from 0.9 to 1 $\theta=$ The Bragg angle.

The average grain size of the AgNPs formed in the bioreduction process determined with the width of the (111) Bragg's reflection using Scherer's formula was estimated at $60 \mathrm{~nm}$. Similar study was reported by Sulaiman et al., 2013 using the leaf extract of Eucalyptus chapmaniana in which the XRD pattern showed $\left(38.50^{\circ}\right.$ and $\left.44.76^{\circ}\right)$ in the whole spectrum of $2 \theta$ value ranging from 20 to 60 and indicated that the structure of AgNP is FCC corresponding to 111 and 200 planes for silver [20]. The high intense peak for FCC materials is generally (111) reflection, which is observed in the fungus, Aspergillus foetidus. The intensity of peaks reflected the high degree of crystallinity of the AgNP [21].

\section{FTIR analysis of biosynthesized AgNPs}

FTIR spectroscopy analysis was used to characterize and identify the biomolecules that were bound specifically on the synthesized AgNPs.

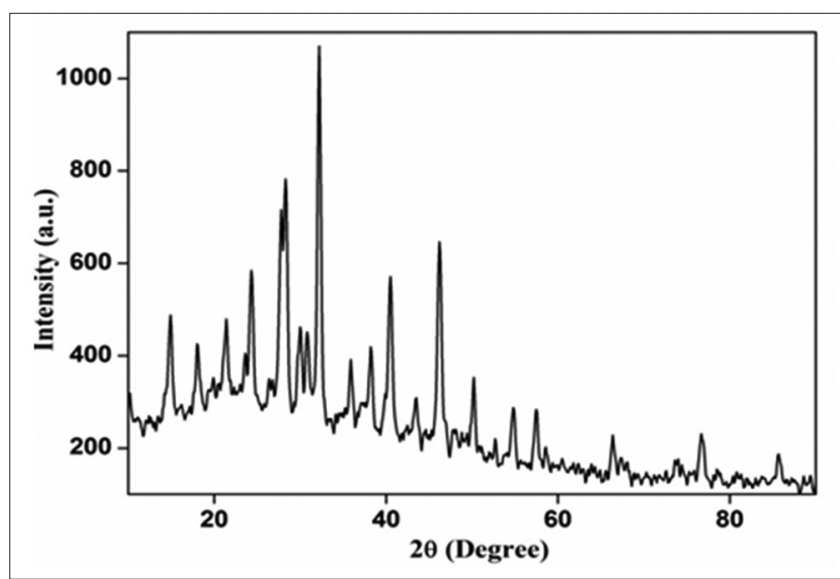

Fig. 4: X-ray diffraction analysis of biosynthesized silver nanoparticles

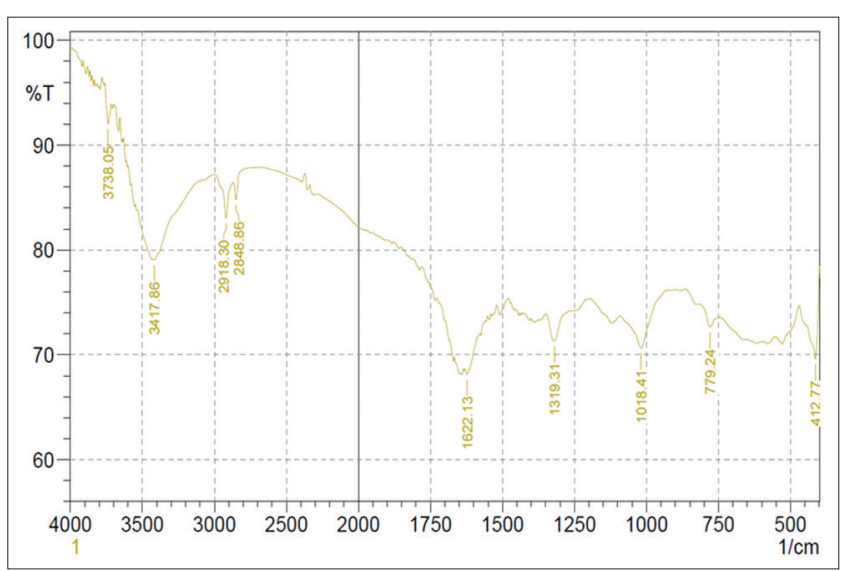

Fig. 5: Fourier transform infrared analysis of biosynthesized silver nanoparticles
FTIR analysis was used to characterize the nature of capping ligands that stabilize the biosynthesized AgNPs formed by bioreduction process.

The spectra were obtained in the wavelength range between 500 and $4000 / \mathrm{cm}$ and the FTIR spectra of before and after aqueous extract addition into silver ion reaction products are given Fig. 5. The peaks appeared at $3417.86 / \mathrm{cm}$ (strong $\mathrm{OH}$-bonding) indicate the presence of $\mathrm{OH}$ stretching of carboxyl groups and $\mathrm{N}-\mathrm{H}$ stretching of secondary amides. Further, these peaks also indicate the presence of bonded hydroxyl groups. The peaks observed at 2918.30, 2848.86/cm represent the C-H stretching bonds. The peaks observed at $1622.73 / \mathrm{cm}$ represent the bonds with $\mathrm{C}-\mathrm{N}$ stretching, $\mathrm{NH}$ and/or $\mathrm{OH}$ deformation, $\mathrm{COO}^{-}$amines and $\mathrm{C}=\mathrm{C}$ aromatic conjugates and $1319.31 / \mathrm{cm}$ represent the $\mathrm{C}-\mathrm{H}$ stretching, vibrations, and $\mathrm{C}-\mathrm{OH}$ stretching vibrations whereas the sharp peaks appeared at $1018.41 / \mathrm{cm}$ and $779.24 / \mathrm{cm}$ represent the $\mathrm{C}-\mathrm{O}$ stretching and aromatic - $\mathrm{CH}$ deformation, respectively. The disappearance of few bands or decrease in intensity of such band can be attributed to reduction of silver ions coupled with oxidation of phenolic compounds.

Nima and Ganesan 2015 reported that the absorption peak located at $1670 / \mathrm{cm}$ can be attributed to the stretching vibrations of $\mathrm{C}=0$, $\mathrm{NH}_{2}$. The absorption at 1400,1452 and $1456 / \mathrm{cm}$ is possibly due to the bending tendency of symmetric $\mathrm{CH}_{3}$ groups within the acetyl and pyruvyl groups as substituents 23, 24 and germinal methyl function, respectively. Peaks around 1191, 1193, and $1122 / \mathrm{cm}$ may be due to the C-N stretching vibrations of aliphatic phenols, peaks around 1336 and $1338 / \mathrm{cm}$ are due to $\mathrm{N}=0$ symmetry stretching typical of the nitro compound and $1521 / \mathrm{cm}$ for silver and gold reaction media may be due to amide I, arising due to carbonyl stretch in proteins, respectively, may lead to the reduction and stabilization of silver and gold nanoparticles, respectively [22].

The carbonyl group from amino acid residues and peptides of proteins has the stronger ability to bind to metal. The proteins from a coat covering the metal nanoparticles prevent agglomeration of the nanoparticles and stabilize them in the medium. From this evidence, it suggests that the biological molecules could possibly perform the function for the formation and stabilization of the AgNPs in aqueous medium [23].

Antioxidant activity of biosynthesized silver nanoparticles (AgNPs)

DPPH antioxidant assay

The antioxidant activity of biosynthesized AgNPs was evaluated using DPPH and reducing assay. As shown in Table 2, DPPH free

Table 2: DPPH antioxidant assay

\begin{tabular}{|c|c|c|c|}
\hline Concentration $(\mu \mathrm{g} / \mathrm{ml})$ & $\begin{array}{l}\text { Biosynthesized } \\
\text { AgNPs }\end{array}$ & BHT & $\mathrm{IC}_{50}(\mu \mathrm{g} / \mathrm{ml})$ \\
\hline 100 & $9.53 \pm 0.450$ & $36.35 \pm 0.76$ & \\
\hline 200 & $11.26 \pm 0.429$ & $47.65 \pm 0.95$ & \\
\hline 300 & $29.16 \pm 0.429$ & $55.63 \pm 1.07$ & $48.32 \pm 1.31$ \\
\hline 400 & $40.36 \pm 0.429$ & $65.72 \pm 0.96$ & \\
\hline 500 & $53.63 \pm 0.492$ & $68.37 \pm 0.66$ & \\
\hline
\end{tabular}

AgNPs: Silver nanoparticles, BHT: Butylated hydroxytoluene,

DPPH: 2, 2-diphenyl-1-picrylhydrazyl

Table 3: FRAP antioxidant assay

\begin{tabular}{ll}
\hline Sample & FRAP mmol (Fe (II)/g extract \\
\hline Biosynthesized AgNPs & $794.65 \pm 9.27$ \\
Ascorbic acid & $2004.87 \pm 33.71$ \\
\hline
\end{tabular}

Values are means of three independent analyses of the extract \pm standard deviation ( $n=3)$. AgNPs: Silver nanoparticles, FRAP: Ferric reducing antioxidant power 
Table 4: Antibacterial activity of biosynthesized silver nanoparticles

\begin{tabular}{llllllll}
\hline Sample & Conc. $(\mu \mathrm{\mu g} /$ well) & \multicolumn{2}{l}{ Zone of inhibition } & & & \\
\cline { 3 - 8 } & & S. aureus & E. coli & B. cereus & P. aeruginosa & P. vulgaris & K. pneumoniae \\
\hline Biosynthesized AgNPs & 500 & $12.33 \pm 0.58$ & $13.33 \pm 0.58$ & $13.00 \pm 0.00$ & $10.00 \pm 0.00$ & $10.00 \pm 0.00$ & $11.33 \pm 0.58$ \\
& 1000 & $13.33 \pm 0.58$ & $14.00 \pm 0.00$ & $13.67 \pm 0.58$ & $11.00 \pm 1.00$ & $10.67 \pm 0.58$ & $12.67 \pm 0.58$ \\
& 1500 & $13.67 \pm 0.58$ & $15.00 \pm 0.00$ & $14.00 \pm 0.00$ & $12.33 \pm 0.58$ & $12.33 \pm 0.58$ & $13.00 \pm 0.00$ \\
Gentamicin & 2000 & $14.67 \pm 0.58$ & $16.33 \pm 0.58$ & $15.33 \pm 0.58$ & $13.33 \pm 0.58$ & $13.00 \pm 0.00$ & $13.67 \pm 0.58$ \\
\hline & 10 & $20.00 \pm 1.00$ & $16.00 \pm 0.00$ & $17.67 \pm 0.58$ & $15.33 \pm 0.58$ & $15.67 \pm 0.58$ & $16.33 \pm 0.58$ \\
\hline
\end{tabular}

Values are means of three independent analysis \pm standard deviation $(\mathrm{n}=3)$. S. aureus: Staphylococcus aureus, E. coli: Escherichia coli, B. cereus: Bacillus cereus,

P. aeruginosa: Pseudomonas aeruginosa, P. aeruginosa: Proteus vulgaris, K. pneumonia: Klebsiella pneumonia, AgNPs: Silver nanoparticles

radical scavenging activity of synthesized AgNPs showed a potent inhibitory effect when compared with gallic acid as a standard ranging from 20 to $100 \mu \mathrm{g} / \mathrm{ml}$. The percentage inhibition of free radical gets increased with increase in concentration of sample. The $\mathrm{IC}_{50}$ value of nanoparticles was found to be $48.32 \mu \mathrm{g} / \mathrm{ml}$. Figure also shows the reducing ability of AgNPs compared with ascorbic acid (vitamin C) as standard. The reducing power of nanoparticles was found to be effective and increased with an increase in concentration.

\section{FRAP antioxidant assay}

The highest antioxidant activity was found in biosynthesized AgNPs from aqueous extract of $A$. cordifolia. The antioxidant activity of biosynthesized AgNPs was $794.65 \pm 9.27 \mathrm{mmol}$ (Fe (II)/g and it is compared with ascorbic acid $2004.87 \pm 33.71$ as shown in Table 3. Most of the phenols are shown to contain high-level antioxidant activity.

\section{Antibacterial activity of biosynthesized AgNPs}

The antibacterial activity of biosynthesized AgNPs was investigated against various pathogenic bacteria of Gram-positive strains ( $S$. aureus and Bacillus cereus) and Gram-negative strains (E. coli, P. aeruginosa, $P$. vulgaris, and K. pneumonia) using the well diffusion method. The results of agar well diffusion assay showed the maximum zone of inhibition with the E. coli $(16.33 \pm 0.58 \mathrm{~mm})$ followed by B. cereus $(15.33 \pm 0.58 \mathrm{~mm})$, S. aureus $(14.67 \pm 0.58 \mathrm{~mm}), K$. pneumonia $(13.67 \pm 0.58)$, P. aeruginosa $(13.33 \pm 0.58)$, and $P$. vulgaris $(13.00 \pm 0.00)$. Table 4 showed the zone of inhibition of the antibacterial activity of biosynthesized AgNPs from A. cordifolia on solid medium. Biosynthesized AgNPs from aqueous extract of A. cordifolia was compared with the standard drug gentamicin.

The biosynthesized AgNPs from aqueous extract of A. cordifolia showed a significant antibacterial activity against the six organisms. The highest zone of inhibition was obtained for E. coli than the B. cereus, P. aeruginosa, S. aureus, P. vulgaris, and K. pneumonia.

It was reported that the bactericidal effect of AgNPs could be attributed to either their interaction with the surface of membrane or to their penetration inside the bacteria. Many studies suggested that silver ions react with SH groups of proteins and play an essential role in bacterial inactivation. Silver ion binds to functional groups of proteins, resulting in protein denaturation, DNA loses its replication ability and cellular proteins become inactivated and finally, cell death occurs [7]. The antibacterial activity of AgNPs on Gram-negative bacteria was dependent on its concentration, and closely associates with the formation of 'pits' in the cell wall of bacteria [24]. Inside a bacterium nanoparticles interact with DNA, failing its ability to replicate, which may lead to cell death [25]. Thus, AgNPs accumulated in the bacterial membrane, increasing its permeability and hence degradation, resulting in cell death. SNPs are nontoxic to humans, effective against bacteria, virus and other eukaryotic microorganism at low concentrations without any side effects. Moreover, several salts of silver and their derivatives are commercially manufactured as antimicrobial agents. In small concentrations, silver is safe for human cells but lethal for microorganisms. Antimicrobial capability of SNPs allows them to be suitably employed in numerous household products such as textiles, food storage containers, home appliances, and in medical devices [26].
It is proved that AgNPs by green synthesis can compete commercial antimicrobial agents used for the treatment of bacterial infections. Silver has shown to prevent binding of HIV to host cells. In addition, silver has been used in water and air filtration to eliminate microorganism [27].

\section{ACKNOWLEDGMENTS}

This research work was funded by University Grants Commission. Authors would like to thank DST-FIST Laboratory, Department of Biochemistry, Dr. N. G. P Arts and Science College to carry out some of this work.

\section{REFERENCES}

1. Durán N, Marcato PD, Alves OL, Souza GI, Esposito E. Mechanistic aspects of biosynthesis of silver nanoparticles by several Fusarium oxysporum strains. J Nanobiotechnology 2005;3:8.

2. Klaus T, Joerger R, Olsson E, Granqvist C. Silver-based crystalline nanoparticles, microbially fabricated. Proceedings of the National Academy of Sciences of the United States of America. Vol. 96. 1999. p. 13611-4.

3. Arora S, Jain J, Rajwade JM, Paknikar KM. Cellular responses induced by silver nanoparticles: In vitro studies. Toxicol Lett 2008;179(2):93-100.

4. Gurunathan S, Kalishwaralal K, Vaidyanathan R, Venkataraman D, Pandian SR, Muniyandi J, et al. Biosynthesis, purification and characterization of silver nanoparticles using Escherichia coli. Colloids Surf B Biointerfaces 2009;74(1):328-35.

5. Pal S, Tak YK, Song JM. Does the antibacterial activity of silver nanoparticles depends on the shape of the nanoparticle? A study of the gram-negative bacterium Escherichia coli. Appl Environ Microbiol 2007;73(6):1712-20.

6. Holt KB, Bard AJ. Interaction of silver(I) ions with the respiratory chain of Escherichia coli: An electrochemical and scanning electrochemical microscopy study of the antimicrobial mechanism of micromolar Ag. Biochemistry 2005;44(39):13214-23.

7. Morones JR, Elechiguerra JL, Camacho A, Holt K, Kouri JB, Ramírez JT, et al. The bactericidal effect of silver nanoparticles. Nanotechnology 2005;16(10):2346-53.

8. Govindaraju K, Tamilselvan S, Kiruthiga V, Singaravelu G. Biogenic silver nanoparticles by Solanum torvum and their promising antimicrobial activity. J Biopest 2010;3(1):394-9.

9. Priya MM, Selvi BK, Paul JA. Green synthesis of silver nanoparticles from the leaf extracts of Euphorbia hirta and Nerium indicum. Digest $\mathbf{J}$ Nanomater Biostruct 2011;6:869-77.

10. Smitha SL, Nissamudeen KM, Philip D, Gopchandran KG. Studies on surface plasmon resonance and photoluminescence of silver nanoparticles. Spectrochim Acta A Mol Biomol Spectrosc 2008;71(1):186-90.

11. Kumar A, Vemula PK, Ajayan PM, John G. Silver-nanoparticleembedded antimicrobial paints based on vegetable oil. Nat Mater 2008;7(3):236-41

12. Raffi M, Rumaiz AK, Hasan MM, Shah SI. Fungal mediated silver nanoparticle synthesis using robust experimental design and its application in cotton fabric. J Mater Res 2007;22:3378-84.

13. Lee KJ, Jun B, Choi J, LeeY, Joung J, Oh YS. Environmentally friendly synthesis organic soluble silver nanoparticles for printed electronics. Nanotechnology 2007:18(33):335-601.

14. Sambhy V, MacBride MM, Peterson BR, Sen A. Silver bromide nanoparticle/polymer composites: Dual action tunable antimicrobial materials. J Am Chem Soc 2006;128(30):9798-808 
15. Huang J, Li Q, Sun D, Lu Y, Su Y, Yang X, et al. Biosynthesis of silver and gold nanoparticles by novel sundried Cinnamomum camphora leaf. Nanotechnology 2007;18(10):105104-14.

16. Salam HA, Rajiv P, Kamaraj M, Jagadeeswaran P, Gunalan S, Sivaraj R. Plants: Green route for nanoparticle synthesis. Int Res J Biol Sci 2012;1(5):85-90.

17. Rajakumar G, Abdul Rahuman A. Larvicidal activity of synthesized silver nanoparticles using Eclipta prostrata leaf extract against filariasis and malaria vectors. Acta Trop 2011;118(3):196-203

18. Deb S. Synthesis and characterization of silver nanoparticles using Brassica oleracea capitata (cabbage) and Phaseolus vulgaris (French beans): A study on their antimicrobial activity and dye degrading ability. Int J ChemTech Res 2014;6(7):3909-17.

19. Firdhouse MJ, Lalitha P. Green synthesis of silver nanoparticles using the aqueous extract of Portulaca oleracea (L.) Asian J Pharm Clin Res 2013;6:92-4

20. Sulaiman GM, Mohammed WH, Marzoog TR, Almiery AA, Kadhum AA, Mohamad AB. Green synthesis, antimicrobial and cytotoxic effects of silver nanoparticles using Eucalyptus chapmaniana leaves extract. Asian Pac J Trop Biomed 2013;3(1):58-3.

21. Roy S, Das TK. Protein capped silver nanoparticles from fungus: X-ray diffraction studies with antimicrobial properties against bacteria. Int $\mathbf{J}$ ChemTech Res 2015;7(3):1452-59.

22. Nima P, Ganesan V. Green synthesis of silver and gold nanoparticles using flower bud broth of Couropita guinensis Aublet. Int J ChemTech Res 2015;7:762-8

23. Sridevi A, Sandhya A, Devi P. Characterisation and antimicrobial studies of leaf assisted silver nanoparticles from Carica papaya: A green synthetic approach. Int J Pharm Pharm Sci 2015;7:143-6.

24. Sondi I, Salopek-Sondi B. Silver nanoparticles as antimicrobial agent: A case study on E. coli as a model for Gram-negative bacteria. J Colloid Interface Sci 2004;275(1):177-82.

25. Raja SB, Suriya J, Sekar V, Rajasekaran R. Biomimetic of silver nanoparticles by Ulva lactuca Seaweed and evaluation of its antibacterial activity. Int J Pharm Pharm Sci 2012;4:139-43.

26. Savithramma N, Rao ML, Rukmini K, Devi PS. Antimicrobial activity of silver nanoparticles synthesized by using medicinal plants. Int J ChemTech Res2011;3(3):1394-02.

27. Ravikumar R, Nithya G, Balu SK, Alagar S, Thandavamoorthy P, Thiruvengadam D. Green synthesis, characterization, antimicrobial and cytotoxic effects of silver nanoparticles using Origanum heracleoticum L. Leaf extract. Int J Pharm Pharm Sci 2015;7:288-93. 